\title{
Evaluation and treatment of intracardiac thrombus in ten neonates
}

\author{
Gamze Demirel • Omer Erdeve • Serife Suna Oguz • \\ Istemi Han Celik • Ugur Dilmen
}

Received: 11 March 2011 /Accepted: 30 March 2011 /Published online: 28 April 2011

(C) Springer-Verlag 2011

Dear Sir,

We read with great interest the recent case report by Kovacikova et al. [3] who demonstrated a thrombus obstructing the right ventricle outflow tract in a neonate with methylenetetrahydrofolate reductase (MTHFR) 677TT genotype. The authors stated that a thrombus in a neonate could be a result of a combination of acquired and congenital thrombogenic risk factors, and a mutation analysis should be performed. Although experience in the pediatric population is increasing, there is still a debate about treatment and prophylaxis. Working at a busy NICU and dealing with extremely low birth weight infants, we have quite some experience with neonatal intracardiac thrombi. We would like to share with the readers the thrombogenic and acquired risk factors of our patients and their treatment outcomes $[1,2]$.

In a recent update, we investigated treatment outcomes in 17 neonates, ten of whom with intracardiac thrombi demonstrated by echocardiography [2]. The mean gestational age of the patients was 28.3 weeks (24-38 weeks); the mean birth weight was $1,433 \mathrm{~g}(570-4,660 \mathrm{~g})$. All patients had umblical catheters and polycythemia. Sepsis and prematurity were the other risk factors in part of them. The characteristics of the developing hemostatic system in the neonatal period is another important etiological factor. A thrombogenic mutation analysis was performed in seven of the patients. A heterozygous MTHFR 677 mutation was found in all of them. A heterozygous FV Leiden mutation was found in two, a heterozygous MTHFR 1298 mutation in three, and homozygocity for the $4 \mathrm{G}$ polymorphism of the PAI-1 gene in two.

G. Demirel $(\bowtie) \cdot$ O. Erdeve $\cdot$ S. S. Oguz $\cdot$ I. H. Celik $\cdot$ U. Dilmen Neonatal Intensive Care Unit, Zekai Tahir Burak Maternity Teaching Hospital, 06300 Altındağ, Ankara, Turkey

e-mail:kgamze@hotmail.com
Although there is no clear consensus on the dosage of the recombinant tissue plasminogen activator (r-tPA), eight of the patients were treated with r-tPA with a dose of $200 \mu \mathrm{g} / \mathrm{kg} / \mathrm{h}$ given as a 6 -h infusion per day for 6 days. One patient died because of sepsis at the day of thrombus detection and could not be treated. All of the patients except the one who died at the day of thrombus detection received also enoxaparin as anticoagulant therapy at a dose of $1.5 \mathrm{mg} / \mathrm{kg} /$ dose administered twice daily subcutaneously. None of the patients experienced therapy-related hemorrhage or other complications. In one patient, retreatment was necessary because of thrombus recurrence at the same site. A clinical improvement was observed in all patients during the first evaluation as complete resolution in five and partial resolution in four of them and a complete decrease in thrombus was achieved in all of them during the follow-up.

We suggest that thrombosis in neonates is a multifactorial disorder. Since thrombus is a result of a combination of acquired and congenital thrombogenic risk factors, a thrombogenic mutation analysis should be performed. We suggest that when used cautiously with supportive care, treatment consisting of r-tPA and LMWH may be a safe and effective approach to clot dissolution in neonates.

\section{References}

1. Aydemir C, Erdeve O, Oguz SS, Altug N, Dilmen U (2010) Successful treatment of Candida albicans endocarditis vegetations with recombinant tissue plasminogen activator in an extremely low birth weight preterm infant. Mycoses. doi:10.1111/j.1439-0507.2010.01893.x

2. Demirel G, Oguz SS, Celik IH, Altug N, Uras N, Erdeve O, Dilmen U (2010) Evaluation and treatment of neonatal thrombus formation in 17 patients. Clin Appl Thromb Hemost. doi:10.1177/1076029610382653

3. Kovacikova L, Skrak P, Zahorec M (2011) Thrombus obstructing the right ventricle outflow tract in a neonate with methylenetetrahydrofolate reductase 677TT genotype. Eur J Pediatr. doi:10.1007/s00431-011-1442-5 